Check for updates

Cite this: Mater. Chem. Front., 2020, 4, 213

Received 1st November 2019,

Accepted 15th November 2019

DOI: 10.1039/c9qm00675c

rsc.li/frontiers-materials

\section{Ultrathin $\mathrm{MnO}_{2}$ nanoflakes grown on $\mathrm{N}$-doped hollow carbon spheres for high-performance aqueous zinc ion batteries $\dagger$}

\author{
Linlin Chen, ${ }^{\mathrm{ab}}$ Zhanhong Yang, (D) *a Fan Cui, ${ }^{\mathrm{ab}}$ Jinlei Meng, ${ }^{\mathrm{ab}}$ Yinan Jiang, ${ }^{\mathrm{ab}}$ \\ Jun Long ${ }^{\text {ab }}$ and Xiao Zeng ${ }^{\text {ab }}$
}

\begin{abstract}
The use of $\mathrm{MnO}_{2}$ as a promising cathode material for aqueous zinc ion batteries (AZIBs) remains challenging, because its inherent poor electrical conductivity and huge volume changes lead to a fast capacity decay, short cycle life, and sluggish electrode kinetics. In this study, ultrathin $\mathrm{MnO}_{2}$ nanoflakes grown on $\mathrm{N}$-doped hollow carbon spheres (defined as $\mathrm{MnO}_{2}-\mathrm{NHCSs}$ ) were prepared via a simple solution-phase route and subsequent hydrothermal process, and then evaluated for their potential as a cathode for AZIBs. Ultrathin $\mathrm{MnO}_{2}$ nanoflakes decorated on NHCSs endow the overall electrode with abundant exposed active sites and excellent electrical conductivity, which could buffer the volumetric expansion and facilitate the charge-transfer kinetics. Owing to these favorable structural characteristics, the as-synthesized $\mathrm{MnO}_{2}-\mathrm{NHCS}$ composite can display a high discharge capacity of $349 \mathrm{~mA} \mathrm{~h} \mathrm{~g}^{-1}$ at $0.1 \mathrm{~A} \mathrm{~g}^{-1}$ after 80 cycles. Significantly, ultra-stable long-term cycling performance of $100 \mathrm{~mA} \mathrm{~h} \mathrm{~g}^{-1}$ with a superior capacity retention of $78.7 \%$ is achieved after 2000 cycles at $2.0 \mathrm{~A} \mathrm{~g}^{-1}$. Such notable electrochemical properties of $\mathrm{MnO}_{2}-\mathrm{NHCS}$ are demonstrated to be superior to that of pure $\mathrm{MnO}_{2}$ hollow spheres $\left(\mathrm{MnO}_{2}-\mathrm{HSs}\right)$ and other previously reported manganese-based oxide cathodes, which is promising for practical applications.
\end{abstract}

\section{Introduction}

Aqueous zinc-based batteries have shown remarkable application prospects in the field of large-scale energy storage owing to their merits of low cost, environmental benignness, low safety risk, high ionic conductivity, and high power capability. Traditional zinc-based batteries, including $\mathrm{Zn}-\mathrm{Mn}, \mathrm{Zn}-\mathrm{Ni}, \mathrm{Zn}-\mathrm{Ag}$ and $\mathrm{Zn}$-Air, are mostly assembled with strongly alkaline $\mathrm{KOH}$ or $\mathrm{NaOH}$ solution as an electrolyte. ${ }^{1,2}$ However, the zinc electrodes suffer from serious corrosion and passivation under these strong alkaline conditions. ${ }^{3}$ What is more serious is the generation of zinc dendrites and irreversible discharge products (such as $\mathrm{ZnO}$, $\mathrm{Zn}(\mathrm{OH})_{2}$, etc. $)$, which makes the cycling stability of the electrodes unsatisfactory. In 2011, Kang et al. ${ }^{4}$ studied the $\mathrm{Zn}-\mathrm{MnO}_{2}$ battery systems by replacing alkaline electrolyte with weakly acidic $\mathrm{ZnSO}_{4}$ aqueous solution, and for the first time proposed the concept of aqueous zinc ion batteries (AZIBs). As expected, the formation of

\footnotetext{
${ }^{a}$ Hunan Province Key Laboratory of Chemical Power Source, College of Chemistry and Chemical Engineering, Central South University, Changsha, 410083, China. E-mail: zhyangcsu611@163.com

${ }^{b}$ Innovation Base of Energy and Chemical Materials for Graduate Students Training, Central South University, Changsha, 410083, China

$\dagger$ Electronic supplementary information (ESI) available. See DOI: 10.1039/c9qm00675c
}

zinc dendrites is greatly suppressed, and the safety and cycle life of the assembled batteries is effectively improved. However, research on AZIBs is still limited by the development of appropriate host materials that can offer high specific capacity and outstanding structural stability upon repeated insertion/extraction of guest ions. ${ }^{5}$

As the earliest studied insertion host for AZIBs, $\mathrm{MnO}_{2}$ displays a relatively high open-circuit voltage of about 1.4-1.5 V, and illustrates outstanding specific capacity and energy density. ${ }^{6,7}$ However, it suffers from poor rate capability and short cycle life owing to its inherent poor conductivity and huge volume changes upon charging and discharging, which hinders its actual application to some extent. ${ }^{8}$ Generally, the large volume variation of $\mathrm{MnO}_{2}$ is closely related to the $\mathrm{Zn}^{2+}$ insertion/extraction or phase transitions with cycling. For example, the orthorhombic unit cell of a mesoporous $\gamma-\mathrm{MnO}_{2}$ phase was expanded by $9.21 \%$ after being fully discharged due to $\mathrm{Zn}$-insertion; ${ }^{9}$ the porous structure of the $\mathrm{MnO}_{2} /$ CNT hybrid cathode prepared by Zhang et al. ${ }^{10}$ was destroyed after 1000 repeated charge and discharge cycles owing to the fast and large volume variation induced by $\mathrm{Zn}^{2+}$ insertion and extraction at high current densities, resulting in a decline in capacity. In order to settle these above issues and harvest high-performance electrode materials, many scholars have carried out a lot of research. Liang's group $^{11}$ compared the volume charges of carbon coated $\mathrm{MnO}$ and 
carbon free MnO under different cycle times. It was found that the change of unit cell parameters of carbon-coated $\mathrm{MnO}$ is very inconspicuous, implying that the carbon coating can effectively buffer the volume variation during $\mathrm{Zn}^{2+}$ insertion/extraction. Furthermore, vanadium-doped $\mathrm{MnO}_{2}$ nanoparticles reported by Alfaruqi et $a .^{12}$ were demonstrated to have a significant improvement in the electrochemical zinc-storage properties, because the introduction of $\mathrm{V}$-ions into the $\mathrm{MnO}_{2}$ framework can not only enhance the electrical conductivity, but also lead to anisotropic extension of the $\mathrm{MnO}_{2}$ lattice. Nevertheless, the cycling stability is still very unsatisfactory, and only a specific discharge capacity of $131 \mathrm{~mA} \mathrm{~h} \mathrm{~g}^{-1}$ can be preserved with a retention rate of $49.2 \%$ after 100 cycles at $66 \mathrm{~mA} \mathrm{~g}^{-1}$. In addition, a graphene scroll-coated $\alpha-\mathrm{MnO}_{2}$ composite was synthesized and investigated as a high performance positive material for AZIBs, ${ }^{13}$ which shows a high capacity of $382.2 \mathrm{~mA} \mathrm{~h} \mathrm{~g}^{-1}$ at $0.3 \mathrm{~A} \mathrm{~g}^{-1}$. Although the cycling performances have been obviously improved, the poor electrochemical kinetics of $\mathrm{MnO}_{2}$ is still a great challenge. To the best of our knowledge, the electrochemical properties of metal oxide electrodes for $\mathrm{Na}^{+}, \mathrm{Li}^{+}$, and $\mathrm{K}^{+}$batteries can be obviously improved by utilizing various effective strategies such as constructing porous and micro \& nano-structures, and carbon coating, etc. In particular, nanostructures with hollow interiors are characterized by highly accessible surface area that can enable sufficient contact between the electrode material and electrolyte and provide big cavities for alleviating structural stresses caused by ion insertion/deintercalation or surface Faraday reaction. ${ }^{14,15}$ Furthermore, composites with carbon-based materials are also favored by many scholars, especially nitrogen-doped carbon, which can greatly improve the reactivity and electrical conductivity of electrode materials by creating extrinsic defects. ${ }^{16}$ However, as far as we know, the combination of hollow structure and highly conductive N-doped carbon for constructing a promising $\mathrm{MnO}_{2}$ cathode of AZIBs has not been reported to date.

In this study, we demonstrate the construction of ultrathin $\mathrm{MnO}_{2}$ nanoflakes grown on the surface of $\mathrm{N}$-doped hollow carbon spheres (NHCSs) as a stable and high-rate cathode material for AZIBs. NHCSs as a growth substrate can effectively promote the uniform distribution of active $\mathrm{MnO}_{2}$ nanosheets, increase the total contact area at the electrode-electrolyte interface, and expose more active sites for the maximum utilization of the active ingredient. The combination of NHCSs also significantly enhances the conductivity of the positive electrode. Meanwhile, the $\mathrm{MnO}_{2}-\mathrm{NHCSs}$ hybrid with a hollow structure possesses a large specific surface area, a large cavity volume, and short ion diffusion path, which is kinetically favorable for ion and electron transport. When used as a cathode for AZIBs, the $\mathrm{MnO}_{2}-\mathrm{NHCS}$ electrode displays a promising electrochemical performance with good rate ability and excellent cycling stability, which presents a high specific discharge capacity of $349 \mathrm{~mA} \mathrm{~h} \mathrm{~g}^{-1}$ at $0.1 \mathrm{~A} \mathrm{~g}^{-1}$ after 80 cycles, and a capacity of $100 \mathrm{~mA} \mathrm{~h} \mathrm{~g}^{-1}$ with a superior retention of $78.7 \%$ after 2000 cycles at a high rate of $2.0 \mathrm{~A} \mathrm{~g}^{-1}$. This outstanding electrochemical performance of $\mathrm{MnO}_{2}-\mathrm{NHCSs}$ is superior to pure $\mathrm{MnO}_{2}$ hollow spheres $\left(\mathrm{MnO}_{2}-\mathrm{HSs}\right)$ and other previously reported manganese-based oxide cathodes. The presented strategy sheds light on the further development of appealing cathode materials for AZIBs and other energy storage systems.

\section{Experimental section}

\subsection{Preparations}

2.1.1. Fabrication of NHCSs. NHCSs were prepared according to the original literature. ${ }^{17}$ Typically, $1 \mathrm{~mL}$ of $\mathrm{NH}_{3} \cdot \mathrm{H}_{2} \mathrm{O}(25-28 \%)$, $80 \mathrm{~mL}$ of deionized water, and $24 \mathrm{~mL}$ of absolute ethanol were mixed under strong mechanical agitation. Next, $1 \mathrm{~mL}$ of tetraethyl orthosilicate (TEOS) was added to the above transparent solution drop by drop under continuous stirring. Afterward, $8 \mathrm{~mL}$ of dopamine hydrochloride aqueous solution with a concentration of $50 \mathrm{mg} \mathrm{mL} \mathrm{m}^{-1}$ was added dropwise and then stirring was maintained for $36 \mathrm{~h}$ at room temperature. The resulting brown products of $\mathrm{SiO}_{2} @$ @polydopamine ( $\left.\mathrm{SiO}_{2} @ \mathrm{PDA}\right)$ spheres were filtered and washed repeatedly with deionized water, and thereafter dried in a vacuum oven at $65{ }^{\circ} \mathrm{C}$. In order to gain the final products of NHCSs, the obtained $\mathrm{SiO}_{2} @ P D A$ was calcined under a $\mathrm{N}_{2}$ atmosphere at $800{ }^{\circ} \mathrm{C}$ for $2 \mathrm{~h}$ with a heating rate of $2{ }^{\circ} \mathrm{C} \mathrm{min}{ }^{-1}$, and then etched in $10 \mathrm{wt} \% \mathrm{HF}$ solution for removing the $\mathrm{SiO}_{2}$ core.

2.1.2. Synthesis of $\mathbf{M n O}_{2}-\mathbf{N H C S s}$. $\mathrm{MnO}_{2}-\mathrm{NHCSs}$ were fabricated by growing $\mathrm{MnO}_{2}$ nanoflakes on the NHCS hard templates under hydrothermal conditions. Briefly, $30 \mathrm{mg}$ of NHCSs used as templates were dispersed into $60 \mathrm{~mL}$ of $20 \mathrm{mM} \mathrm{KMnO}_{4}$ aqueous solution under ultrasound guidance for $30 \mathrm{~min}$. Then, the resultant mixture was sealed to a Teflon-lined reaction vessel with a capacity of $100 \mathrm{~mL}$ and hydrothermally treated at $140{ }^{\circ} \mathrm{C}$ for $2 \mathrm{~h}$. After cooling down to room temperature, the as-synthesized powder was collected by centrifugation and washed with deionized water. Finally, the obtained product was dried overnight under vacuum at $65{ }^{\circ} \mathrm{C}$ for further study.

2.1.3. Synthesis of $\mathbf{M n O}_{2}$-HSs for comparison. The preparation of $\mathrm{MnO}_{2}$-HSs for comparison is as follows: firstly, the $\mathrm{SiO}_{2}$ microspheres were prepared by using the Stober method. ${ }^{18}$ Then the as-synthesized $\mathrm{SiO}_{2}$ microspheres $(0.3 \mathrm{~g})$ were dispersed into $60 \mathrm{~mL}$ of $20 \mathrm{mM} \mathrm{KMnO}_{4}$ aqueous solution, and hydrothermally reacted in a stainless steel autoclave at $140{ }^{\circ} \mathrm{C}$ for $2 \mathrm{~h}$. The resulting solid of $\mathrm{MnO}_{2} / \mathrm{SiO}_{2}$ spheres was filtered and rinsed three times with deionized water, and then dried under vacuum at $65{ }^{\circ} \mathrm{C}$. After removing the silica component by etching in $2 \mathrm{M}$ $\mathrm{NaOH}$ solution, the final products of $\mathrm{MnO}_{2}$-HSs were gained.

\subsection{Material characterization}

Crystallographic phases of the as-fabricated product and cycled electrodes were studied by using PANalytical Empyrean XRD system with $\mathrm{Cu} \mathrm{K} \alpha$ radiation. The surface element valence states of samples were examined using a Phi Quantum 2000 spectrophotometer with $\mathrm{Al} \mathrm{K} \alpha$ radiation. The cycled electrodes recorded for ex situ XRD and XPS analysis were prepared as follows: (i) it was charged or discharged with constant current to specific voltages and different cycles; (ii) disassemble the batteries and pick the corresponding cathodes out; (iii) rinse the electrode thoroughly with deionized water after removing the adhered white fibers from it; (iv) dry under vacuum for measurement. Thermogravimetric analysis (TGA) was conducted on a Netzsch STA 2500 thermal instrument in air. 
An FEI Helios NanoLab G3 UC scanning electron microscope (SEM) and JEM-2100F transmission electron microscope (TEM) were implemented to analyze the appearance of the as-prepared samples. Specific surface area and pore structure characteristics of the samples were tested by $\mathrm{N}_{2}$ adsorption/desorption isotherms at $-196{ }^{\circ} \mathrm{C}$ on a Mike ASAP 2460 analyzer.

\subsection{Electrochemical measurements}

To investigate the effects of carbon decoration and microstructure on the electrode performance of $\mathrm{MnO}_{2}$ for AZIBs, CR 2025 coin batteries were constructed by using $\mathrm{MnO}_{2}-\mathrm{NHCSs}$ or $\mathrm{MnO}_{2}-\mathrm{HSs}$ as a cathode, metallic zinc foil as an anode, waterman GF/D glass microfiber filters as the separator, and a mixed aqueous solution containing $3 \mathrm{M} \mathrm{ZnSO}_{4}$ and $0.15 \mathrm{M} \mathrm{MnSO}_{4}$ as an electrolyte $(\mathrm{pH}=4.3)$. The cathode was fabricated by mixing active material, conductive agent (super P) and polytetrafluoroethylene binder (PTFE, Daikin D210C, 5\% of emulsion in water, average particle size $181 \mathrm{~nm}$ ) in a weight proportion of $7: 2: 1$. After sufficient grinding, the mixed slurry was made into a film and cut into several $\varnothing$ $10 \mathrm{~mm}$ coins. Lastly, these coins were pressed onto current collector titanium meshes that had been washed several times with acetone, absolute ethanol and deionized water before use, and dried under vacuum at $65{ }^{\circ} \mathrm{C}$ overnight. The mass loading of the active material is around $1.3-1.6 \mathrm{mg} \mathrm{cm}^{-2}$. Galvanostatic charging and discharging (GCD) experiments were performed on a Neware-battery testing system within the potential window of $1.0-1.85 \mathrm{~V}$ (versus $\mathrm{Zn} / \mathrm{Zn}^{2+}$ ). Besides, cyclic voltammetry (CV) and electrochemical impedance spectroscopy (EIS) measurements were conducted using an electrochemical workstation (CHI 660E). The EIS plots were recorded at a frequency range of $10^{-2}$ to $10^{5} \mathrm{~Hz}$ with an amplitude of $5 \mathrm{mV}$.

\section{Results and discussion}

The typical procedure for the fabrication of $\mathrm{MnO}_{2}-\mathrm{NHCSs}$ is schematically illustrated in Fig. S1 (ESI $\dagger$ ). Firstly, TEOS as a structure-assistant agent is first hydrolyzed to form $\mathrm{SiO}_{2}$ cores in an appropriate amount of ammonia aqueous solution, and then PDA as a carbon precursor derived from the polymerization of DA is deposited on the outer surface of the silicon cores, resulting in a core-shell structure of $\mathrm{SiO}_{2} @ P D A .{ }^{17}$ Second, the precursor is subjected to heat treatment and HF leaching to carbonize the PDA polymer and remove the silicon template to get the NHCSs. Finally, $\mathrm{MnO}_{2}$ nanoflakes are grown on the surface of NHCSs by a redox reaction and an in situ self-limiting deposition method under hydrothermal conditions. ${ }^{19}$ The morphologies and microstructures of the as-prepared NHCS, $\mathrm{MnO}_{2}-\mathrm{NHCS}$, and $\mathrm{MnO}_{2}$-HS samples were characterized by SEM and TEM. It can be seen from Fig. 1a that the NHCSs appeared in uniform spherical shape with relatively smooth surface. The TEM images (Fig. 1b) present the typical hollow nanostructure feature of these spheres with an average diameter of about $250 \mathrm{~nm}$ and a shell thickness of $20 \mathrm{~nm}$. The hollow carbon spheres with large cavity can be used as a good substrate for the growth of $\mathrm{MnO}_{2}$. Fig. 1c shows the SEM photograph of the $\mathrm{MnO}_{2}-\mathrm{NHCS}$ composites, from which flower-like spherical morphology assembled by numerous interconnected ultrathin $\mathrm{MnO}_{2}$ nanoflakes is observed. In addition, it can be clearly seen that these nanosheets grow vertically on the outer surface of NHCSs (Fig. 1d), and their thickness is very thin, which is conducive to providing sufficient active sites for electrochemical reactions. Fig. S2a and b (ESI $\dagger$ ) show the high-resolution TEM photographs of the $\mathrm{MnO}_{2}-\mathrm{NHCS}$ sample. It can be noticed that the clear lattice fringes with interplanar distance of 0.70 and $0.24 \mathrm{~nm}$ can match well with the (001) and (111) lattice planes of birnessite-type $\mathrm{MnO}_{2}$. The selected area electron diffraction (SAED) pattern (Fig. S2c, ESI $\dagger$ ) indicates its polycrystalline nature and poor crystallinity. For convenience of comparison, the microstructure of $\mathrm{MnO}_{2}$-HSs is also analyzed, whose growth substrate is uniform $\mathrm{SiO}_{2}$ spheres with a diameter of about $280 \mathrm{~nm}$ (Fig. S3, ESI $\dagger$ ). As demonstrated in Fig. 1e and $\mathrm{f}$, the $\mathrm{MnO}_{2}$-HS samples exhibit a similar morphology to that of
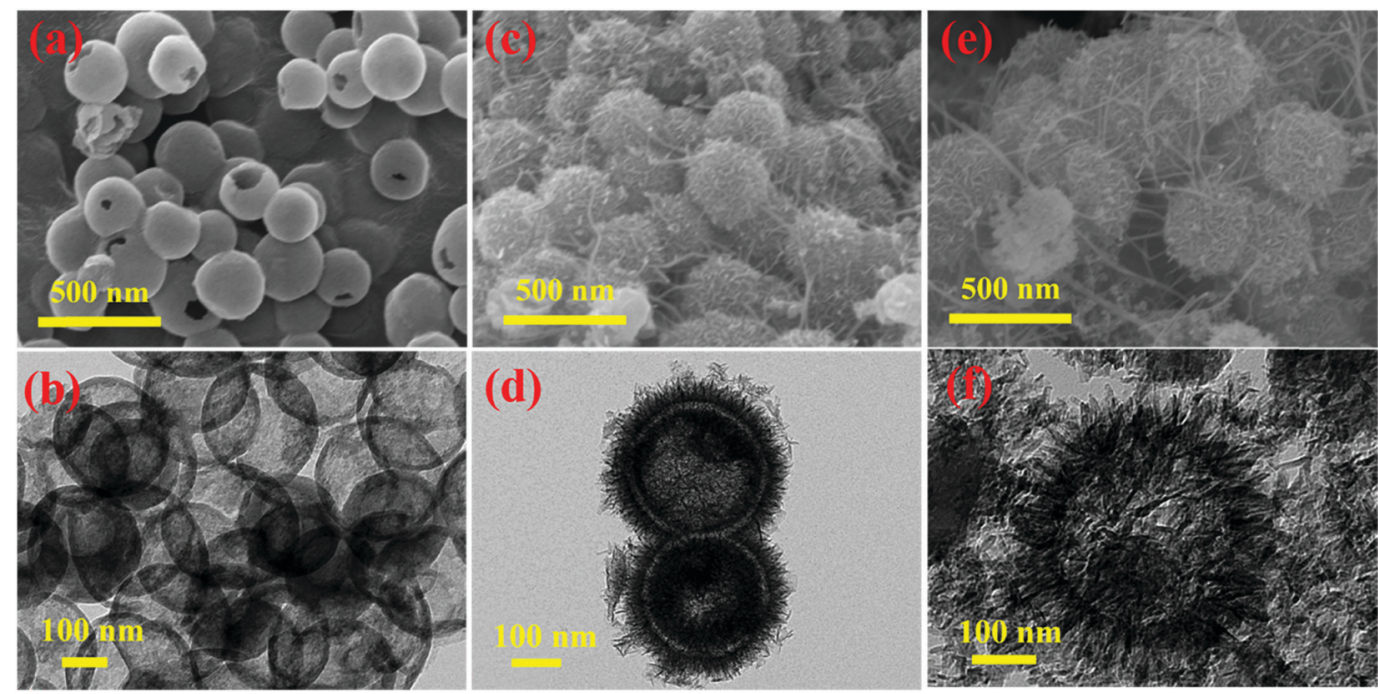

Fig. 1 SEM and TEM photographs of (a and b) NHCS, (c and d) $\mathrm{MnO}_{2}-\mathrm{NHCS}$, and (e and f) $\mathrm{MnO}_{2}-\mathrm{HS}$ samples. 
$\mathrm{MnO}_{2}$-NHCS, except for the inner carbon core displayed in the TEM image. Meanwhile, the surface $\mathrm{MnO}_{2}$ nanosheets grow larger and irregular compared to $\mathrm{MnO}_{2}-\mathrm{NHCS}$.

The XRD patterns of the as-prepared materials are displayed in Fig. 2a. In particular, a broad X-ray diffraction peak of NHCSs at $2 \theta$ values of $25.2^{\circ}$ can be indexed to the (002) Bragg's reflection plane of the highly graphitized carbon. ${ }^{20,21}$ For $\mathrm{MnO}_{2}-\mathrm{NHCS}$ and $\mathrm{MnO}_{2}$-HS samples, the four characteristic peaks at $12.6^{\circ}, 24.9^{\circ}, 37.1^{\circ}$, and $65.5^{\circ}$ correspond well with the (001), (002), (111), and (020) faces of birnessite-type $\mathrm{MnO}_{2}$ (JCPDs No. 42-1317) with space group $C 2 / m$ (a monoclinic unit cell with $a=5.15 \AA, b=2.844 \AA, c=7.159 \AA)$. The crystal structure of 2D layered birnessite-like $\mathrm{MnO}_{2}$ is constructed by layers of edge-sharing $\mathrm{MnO}_{6}$ octahedra, and the interlayer space is typically filled with a certain number of crystallographically bonded water molecules and foreign cations, which play a role in stabilizing the layered structure and balancing the charges. $^{22}$ The large interlayer distance along the 001 diffraction direction is theoretically advantageous for the storage and transportation of zinc ions. Meanwhile, the broadened and weak diffraction peaks reveal a poor crystallization of the obtained $\mathrm{MnO}_{2}$ samples. The Raman spectra of the harvested three samples are displayed in Fig. 2b. For the NHCS sample, two peaks at 1342 and $1590 \mathrm{~cm}^{-1}$ are observed, which can be assigned to the defected or disordered graphitic structure (D band) and the crystallized graphite peak ( $G$ band), respectively. ${ }^{23}$ After the incorporation of $\mathrm{MnO}_{2}$ on NHCSs, the $I_{\mathrm{D}} / I_{\mathrm{G}}$ values used to analyze the structural defects are slightly increased from 1.02 to 1.08 , implying that more structural defects are formed in the hybrids. Besides the Raman response from the carbon components, the peaks at 573 and $640 \mathrm{~cm}^{-1}$ can be ascribed to the typical vibrational results of birnessite-type $\mathrm{MnO}_{2}$ compounds. ${ }^{24}$ Among those bands, the peak at $573 \mathrm{~cm}^{-1}$ is related to the $\nu_{3}(\mathrm{Mn}-\mathrm{O})$ stretching vibration in the basal plane of $\left[\mathrm{MnO}_{6}\right]$ sheets; while the peak at $640 \mathrm{~cm}^{-1}$ is attributed to the $\nu_{2}(\mathrm{Mn}-\mathrm{O})$ symmetric stretching vibration of the $\left[\mathrm{MnO}_{6}\right]$ octahedron. ${ }^{25,26}$ The surface elemental compositions and valence states of $\mathrm{MnO}_{2}-\mathrm{NHCSs}$ were investigated through XPS characterization. From the XPS survey spectrum shown in Fig. 2c, the main peaks corresponding to $\mathrm{Mn}, \mathrm{O}, \mathrm{C}$, and $\mathrm{N}$ elements are observed. Fig. 2d displays the high resolution Mn2p XPS spectrum, in which two peaks at 642.4 and $653.9 \mathrm{eV}$ are indicative of $\mathrm{Mn} 2 \mathrm{p}_{1 / 2}$ and $\mathrm{Mn} 2 \mathrm{p}_{3 / 2}$. And the energy difference of $11.5 \mathrm{eV}$ between these two bands is detected, displaying good consistency with the location of the tetravalent manganese $\mathrm{Mn}^{4+} \cdot{ }^{27}$ The C1s core level spectrum presented in Fig. 2e can be deconvoluted into four components, which are $\mathrm{C}-\mathrm{C} / \mathrm{C}=\mathrm{C}(284.7 \mathrm{eV})$, $\mathrm{C}-\mathrm{N}(285.4 \mathrm{eV}), \mathrm{C}-\mathrm{O}(286.3 \mathrm{eV})$ and $\mathrm{O}-\mathrm{C}=\mathrm{O}(288.4 \mathrm{eV}) .{ }^{28,29}$ It is noteworthy that the existence of a $\mathrm{C}-\mathrm{N}$ bond indicates successful introduction of an $\mathrm{N}$ element to the carbon material using aqueous ammonia solution. As for the $\mathrm{N}$ 1s core-level spectrum shown in Fig. 2f, four types of nitrogen chemical states that arise from pyridinic- $\mathrm{N}(398.3 \mathrm{eV})$, pyrrolic-N $(399.8 \mathrm{eV})$, quaternary-N $(400.9 \mathrm{eV})$, and oxidized pyridinic-N $(403.2 \mathrm{eV})$ are noticed. ${ }^{27}$ It is generally believed that nitrogen doping can create some defects, provide conjugated electrons, and further enhance the electrical conductivity of electrode materials.

In order to gain an intuitive vision into the pore structure of $\mathrm{MnO}_{2}-\mathrm{NHCS}$ and $\mathrm{MnO}_{2}$-HS samples, the $\mathrm{N}_{2}$ adsorption/desorption isotherms and corresponding pore size distribution profiles were studied, as presented in Fig. 3. Based on the IUPAC definition, both samples exhibit a typical type-IV adsorption isotherm with H3 hysteresis loop. This kind of hysteresis loop is generally considered to be the feature of slit-shaped mesopores, which arise from the vertical growth of numerous $\mathrm{MnO}_{2}$ nanoflakes. ${ }^{3,30}$ According to the Brunauer-Emmett-Teller (BET) and Barrett-Joyner-Halenda (BJH) equations, the calculated parameters such as specific surface area, pore volume and average pore size of these two samples are recorded in Table S1. The $\mathrm{MnO}_{2}-\mathrm{NHCS}$ sample exhibits a higher
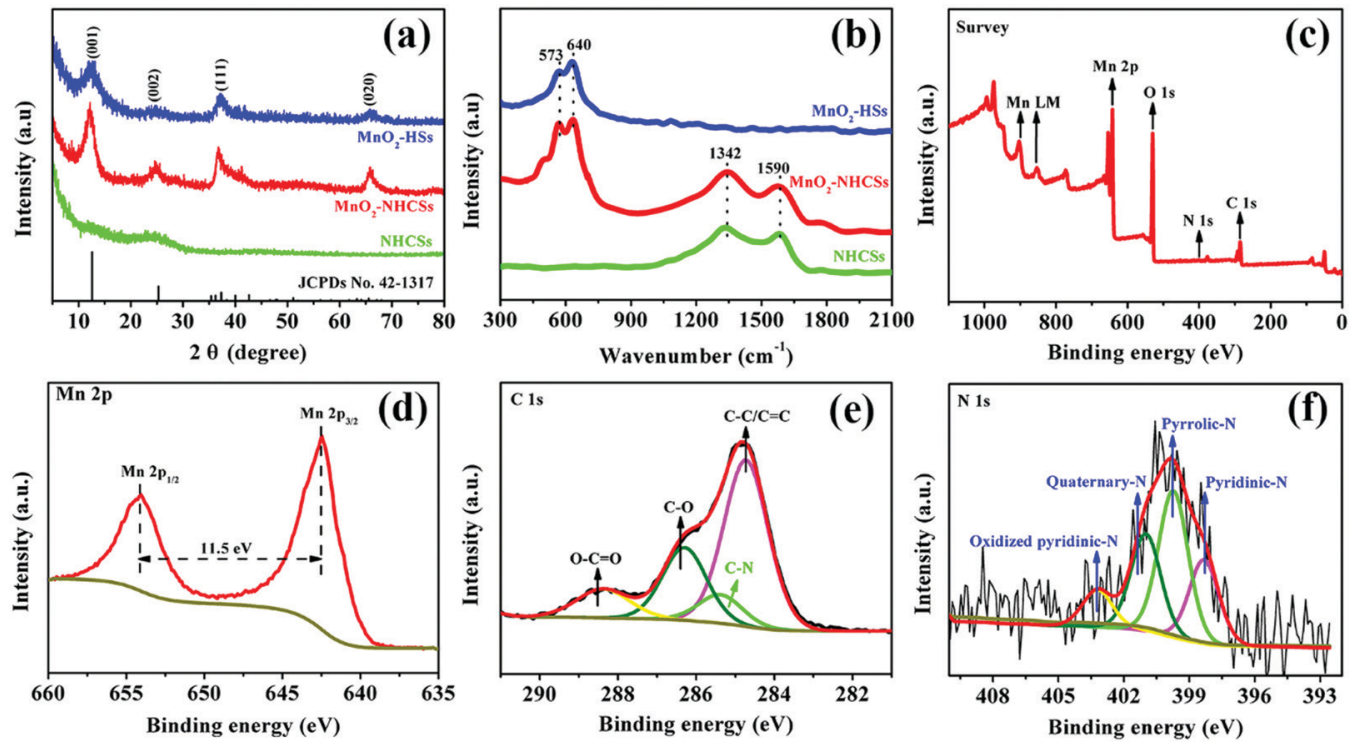

Fig. 2 (a) XRD patterns and (b) Raman spectra of $\mathrm{NHCSs}_{1} \mathrm{MnO}_{2}-\mathrm{NHCSs}$, and $\mathrm{MnO}_{2}-\mathrm{HSS}$. (c) XPS full spectrum of $\mathrm{MnO}_{2}-\mathrm{NHCSs}$. (d, e, and f) The corelevel XPS spectra for $\mathrm{Mn} 2 \mathrm{p}, \mathrm{C} 1 \mathrm{~s}$, and $\mathrm{N}$ 1s of $\mathrm{MnO}_{2}-\mathrm{NHCSs}$, respectively. 

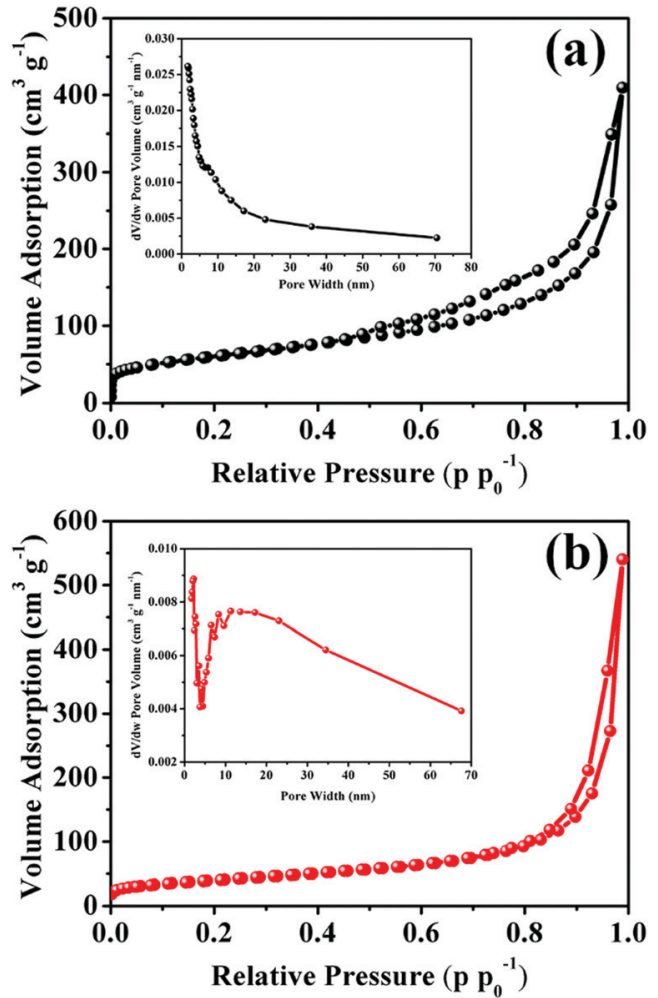

Fig. $3 \quad \mathrm{~N}_{2}$ adsorption-desorption isotherms and the corresponding pore size distribution profiles (inset) of (a) $\mathrm{MnO}_{2}-\mathrm{NHCSs}$ and (b) $\mathrm{MnO}_{2}-\mathrm{HSs}$.

surface area of $213.12 \mathrm{~m}^{2} \mathrm{~g}^{-1}$ relative to that of $\mathrm{MnO}_{2}$-HSs $\left(141.24 \mathrm{~m}^{2} \mathrm{~g}^{-1}\right)$. Meanwhile, the $\mathrm{BJH}$ pore size distribution (inset of Fig. 3a and b) reveals that the pore widths of both samples vary over a wide range, featuring a hierarchical pore structure. Among them, the average pore size of $\mathrm{MnO}_{2}-\mathrm{NHCSs}$ is relatively small and uniformly distributed. A large specific surface area and suitable hierarchical pore distribution can not only decrease the diffusion path length of ions and thus facilitate the infiltration and migration of electrolyte ions throughout the whole electrode materials, but also boost the homogeneous accumulation of electrical charges at the electrode-electrolyte interface. ${ }^{15,27}$ This structural architecture is highly beneficial for electrochemical reactions. Thermogravimetric analysis (TGA) was employed to evaluate the thermal stability of $\mathrm{MnO}_{2}-\mathrm{NHCSs}$ and $\mathrm{MnO}_{2}-\mathrm{HSs}$, and the results indicate that the mass ratio of NHCSs in the $\mathrm{MnO}_{2}-\mathrm{NHCS}$ hybrid is about $10.2 \mathrm{wt} \%$ (Fig. S4, ESI $\dagger$ ).

Type 2025 coin batteries were constructed to explore various electrochemical properties. Fig. 4a displays the $\mathrm{CV}$ profiles of $\mathrm{MnO}_{2}-\mathrm{NHCSs}$ at a sweep rate of $0.5 \mathrm{mV} \mathrm{s}^{-1}$ within the voltage window of 1.0-1.85 V. During the first cathodic scan, a strong reduction peak appears at $1.17 \mathrm{~V}$, which is associated with the insertion of $\mathrm{Zn}^{2+}$ and the reduction of $\mathrm{Mn}^{4+}$ to $\mathrm{Mn}^{3+} / \mathrm{Mn}^{2+}$ states. Conversely, an oxidation peak located at $1.60 \mathrm{~V}$ is observed during the anodic scan, corresponding to the $\mathrm{Zn}^{2+}$ extraction and reinstatement of $\mathrm{Mn}^{4+}$. However, the $\mathrm{CV}$ curves in the following cycles are slightly different, with the former cathodic peak shifting toward higher voltage $(\sim 1.25 \mathrm{~V})$ and a new peak appearing at $1.36 \mathrm{~V}$, which is similar to the $\mathrm{CV}$ response of other
Mn-based electrodes reported in the literature. ${ }^{31}$ It should be noted that the $\mathrm{CV}$ curves coincide well after the first five sweeps, demonstrating good stability and reversibility of the $\mathrm{MnO}_{2}-\mathrm{NHCS}$ electrode. Fig. 4b compares the $\mathrm{CV}$ profiles of $\mathrm{MnO}_{2}-\mathrm{NHCSs}$ and $\mathrm{MnO}_{2}$-HSs, from which we can see that the $\mathrm{MnO}_{2}-\mathrm{NHCS}$ electrode exhibits a slightly higher current density and reduced potential separation among the oxidation and reduction peaks compared with that of $\mathrm{MnO}_{2}-\mathrm{HSs}$, indicating a substantial improvement of the electrochemical capacitance and reversibility due to the incorporation of NHCSs and favorable structure with high specific surface area and suitable hierarchical pore distribution. Generally, the voltage difference for charging/discharging potential platforms is related to the electrode polarization in the electrochemical reaction processes. As shown in Fig. 4c, the potential differences of $\mathrm{MnO}_{2}-\mathrm{NHCSs}$ in the first and second plateaus are 95 and $310 \mathrm{mV}$, respectively, which is lower than that of the $\mathrm{MnO}_{2}$-HSs electrode, further verifying the decrease of electrochemical polarization and the improvement of electrode reversibility. The average discharge and charge voltage of the $\mathrm{MnO}_{2}-\mathrm{NHCS}$ electrode were calculated to be 1.362 and $1.569 \mathrm{~V}$ (Fig. S5, ESI $\dagger$ ). The cycling stability of $\mathrm{MnO}_{2}-\mathrm{NHCSs}$ and $\mathrm{MnO}_{2}$-HSs at $0.1 \mathrm{~A} \mathrm{~g}^{-1}$ was studied comparatively, as presented in Fig. $4 \mathrm{~d}$. The average specific discharge capacity of $\mathrm{MnO}_{2}-\mathrm{NHCSs}$ during the initial several cycles is about $350 \mathrm{~mA} \mathrm{~h} \mathrm{~g}{ }^{-1}$, which is slightly superior to that of $\mathrm{MnO}_{2}$-HSs (330 $\mathrm{mA} \mathrm{h} \mathrm{g}{ }^{-1}$ ). However, the electrode with $\mathrm{MnO}_{2}$-HSs suffers from strong capacity fading, and it delivers a discharge capacity of $266 \mathrm{~mA} \mathrm{~h} \mathrm{~g}^{-1}$ with about $80.6 \%$ capacity retention after 80 cycles, which is obviously not comparable to the $\mathrm{MnO}_{2}-\mathrm{NHCS}$ electrode (349 $\mathrm{mA} \mathrm{h} \mathrm{g}^{-1}$ without capacity loss after 80 cycles). In order to get the underlying reasons why the electrochemical behavior of $\mathrm{MnO}_{2}-\mathrm{NHCSs}$ is more advanced than that of $\mathrm{MnO}_{2}$-HSs, EIS analysis was performed (Fig. 4e). The impedance curves of these two samples are all built up of a semicircle in the high frequency area and an oblique straight line in the low frequency range, wherein the semicircle diameter is considered to be related to the charge transfer impedance $\left(R_{\mathrm{ct}}\right)$ at the electrolyte/electrode interface. Surprisingly, the $R_{\mathrm{ct}}$ value of $612 \Omega$ for $\mathrm{MnO}_{2}-\mathrm{NHCSs}$ is much lower than that of $\mathrm{MnO}_{2}$-HSs (940 $\Omega$ ) due to the modification with $\mathrm{N}$-doped carbon, and its $R_{\text {ct }}$ values are greatly reduced during the initial first five cycles and is still smaller than that of the pure $\mathrm{MnO}_{2}$ sample (Fig. S6, ESI $\dagger$ ), which enables rapid charge transfer within the electrode materials, thus resulting in an improved electrochemical performance. For both samples, the decrease in the charge transfer resistance with initial cycling can be explained by the following: as the cell is cycled, the electrolyte can be sufficiently wetted the previously inaccessible regions in the interior of electrode particles, resulting in an increase of the active surface area available for reaction. ${ }^{32}$ Meanwhile, the diffusion paths of $\mathrm{Zn}^{2+}$ could be gradually developed with the penetration of an electrolyte, leading to an improvement of the reaction kinetics. ${ }^{33}$

Rate performance is of vital importance for practical applications due to the increasing demand for fast charging. So the rate capability of $\mathrm{MnO}_{2}-\mathrm{NHCSs}$ and $\mathrm{MnO}_{2}$ - $\mathrm{HSs}$ was studied 

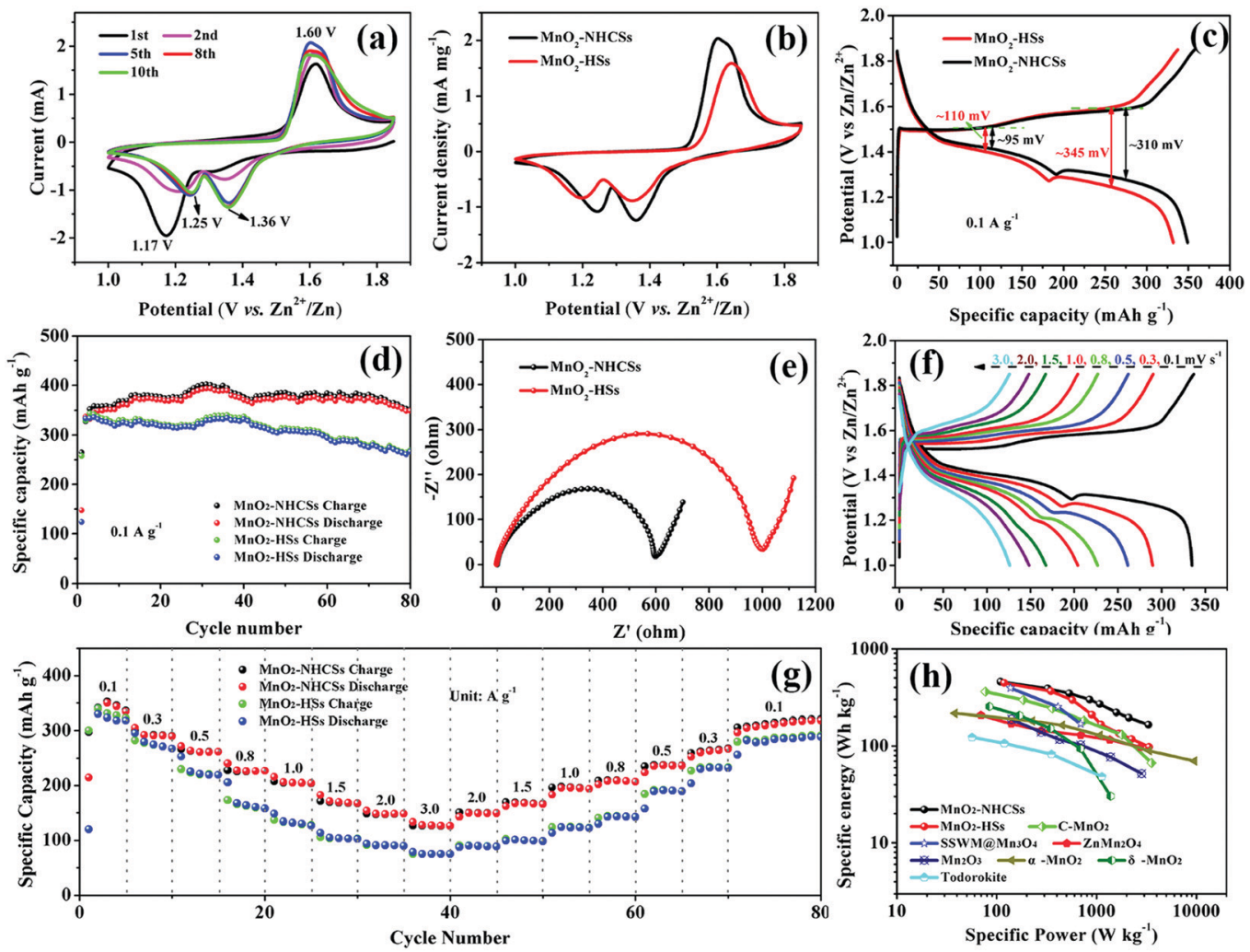

Fig. 4 (a) $\mathrm{CV}$ curves of $\mathrm{MnO}_{2}-\mathrm{NHCSs}$ at $0.5 \mathrm{mV} \mathrm{s}^{-1}$, (b) comparison of $\mathrm{CV}$ profiles of $\mathrm{MnO}_{2}-\mathrm{NHCSs}$ and $\mathrm{MnO}_{2}-\mathrm{HSs}$ at $0.5 \mathrm{mV}$ s ${ }^{-1}$, (c) GCD profiles of $\mathrm{MnO}_{2}-\mathrm{NHCSs}$ and $\mathrm{MnO}_{2}-\mathrm{HSs}$ for the 5th cycle, (d) the cycling performance at $0.1 \mathrm{~A} \mathrm{~g}^{-1}$, (e) Nyquist plots of $\mathrm{MnO}_{2}-\mathrm{NHCSs}$ and $\mathrm{MnO} \mathrm{O}_{2}-\mathrm{HSs}$, (f) GCD profiles of $\mathrm{MnO}_{2}-\mathrm{NHCSs}$ under various current rates, (g) rate performance of $\mathrm{MnO}_{2}-\mathrm{NHCSs}$ and $\mathrm{MnO}_{2}-\mathrm{HSs}$, and (h) Ragone plots of $\mathrm{MnO}_{2}-\mathrm{NHCSs}$ compared with other reported manganese oxide-based electrodes.

through charging and discharging under varied current densities from 0.1 to $3.0 \mathrm{~A} \mathrm{~g}^{-1}$. As observed in Fig. $4 \mathrm{~g}$, when cycled at $0.1,0.3$, $0.5,0.8,1.0,1.5$, and $2.0 \mathrm{~A} \mathrm{~g}^{-1}$, the reversible capacities of $\mathrm{MnO}_{2}-$ NHCSs are $\sim 348,293,262,227,204,168$, and $149 \mathrm{~mA} \mathrm{~h} \mathrm{~g}{ }^{-1}$, respectively. Conspicuously, the capacity still remained as high as $127 \mathrm{~mA} \mathrm{~h} \mathrm{~g}{ }^{-1}$ at an extremely high current density of $3.0 \mathrm{~A} \mathrm{~g}^{-1}$. When the current gradually switched back to $0.1 \mathrm{~A} \mathrm{~g}^{-1}$, the discharge capacity could recover to $318 \mathrm{~mA} \mathrm{~h} \mathrm{~g}^{-1}$ with $91.3 \%$ capacitance retention undergoing 80 rate cycles, displaying excellent rate performance and fast reaction kinetics. In contrast, the capacities of $\mathrm{MnO}_{2}$-HSs rapidly decreased with increasing current densities, and only $74 \mathrm{~mA} \mathrm{~h} \mathrm{~g}^{-1}$ is maintained at a high rate of $3 \mathrm{~A} \mathrm{~g}^{-1}$. The above results indicate that $\mathrm{MnO}_{2}-\mathrm{NHCSs}$ have more superior rate performance than $\mathrm{MnO}_{2}$-HSs, which can be explained by the following aspects: (i) the presence of nitrogen-doped carbon spheres as the substrate could effectively enhance the conductivity of electrode materials and thus improve the electron transfer during the redox reaction; (ii) attachment of $\mathrm{MnO}_{2}$ to the carbon sphere skeleton is advantageous for maintaining structural stability such that the electrode can withstand the impact of large currents during cycling. GCD curves of $\mathrm{MnO}_{2}-\mathrm{NHCSs}$ at different current rates are presented in Fig. 4f. Interestingly, with the increase in current densities, the second discharge platform below 1.3V (demarcation by turning point, see Fig. S7a, ESI $\dagger$ ) gradually becomes invisible, and its contribution to the total capacity decreases significantly
(Fig. S7b, ESI $\dagger$ ), implying that the electrode reaction kinetics in this low discharge plateau region is not as good as that in the upper voltage region. Meanwhile, the battery assembled with our prepared $\mathrm{MnO}_{2}-\mathrm{NHCSs}$ electrode was able to deliver a maximum energy density of $457 \mathrm{~W} \mathrm{~h} \mathrm{~kg}^{-1}$ at a power density of $109 \mathrm{~W} \mathrm{~kg}^{-1}$, and a maximum power density of $3313 \mathrm{~W} \mathrm{~kg}^{-1}$ at an energy density of $165 \mathrm{~W} \mathrm{~h} \mathrm{~kg}{ }^{-1}$, which outperforms most recently reported manganese oxide-based electrodes, such as C- $\mathrm{MnO}_{2},{ }^{25} \mathrm{ZnMn}_{2} \mathrm{O}_{4},{ }^{34}$ SSWM@Mn $\mathrm{O}_{4},{ }^{35} \mathrm{Mn}_{2} \mathrm{O}_{3},{ }^{36} \alpha-\mathrm{MnO}_{2},{ }^{4} \delta-\mathrm{MnO}_{2},{ }^{37}$ todorokite, ${ }^{38}$ etc.

The excellent rate performance of the $\mathrm{MnO}_{2}-\mathrm{NHCS}$ electrode motivated us to further explore the electrochemical reaction kinetics. Fig. 5a displays the $\mathrm{CV}$ curves of $\mathrm{MnO}_{2}-\mathrm{NHCSs}$ at different sweep rates ranging from 0.1 to $1.0 \mathrm{mV} \mathrm{s}^{-1}$. It can be noticed that the shapes of the CV curves are basically the same with the promoted scan rates, except for the increased peak current and peak shift, suggesting good structural stability of the $\mathrm{MnO}_{2}-\mathrm{NHCS}$ electrode. The electrochemical kinetics can usually be evaluated through the quantitative relationship between the peak intensity in current $(i)$ and the sweeping rates $(v) .{ }^{39}$

$$
i=a v^{b}
$$

According to the equation, the $b$ values can be fitted by the linearity of $\log (i) v s . \log (v)$. A $b$ slope of 0.5 suggests a diffusiondominated $\mathrm{Zn}^{2+}$ intercalation mechanism, while a $b$ value near to 1.0 illustrates a surface-limited capacitive behavior. As shown 

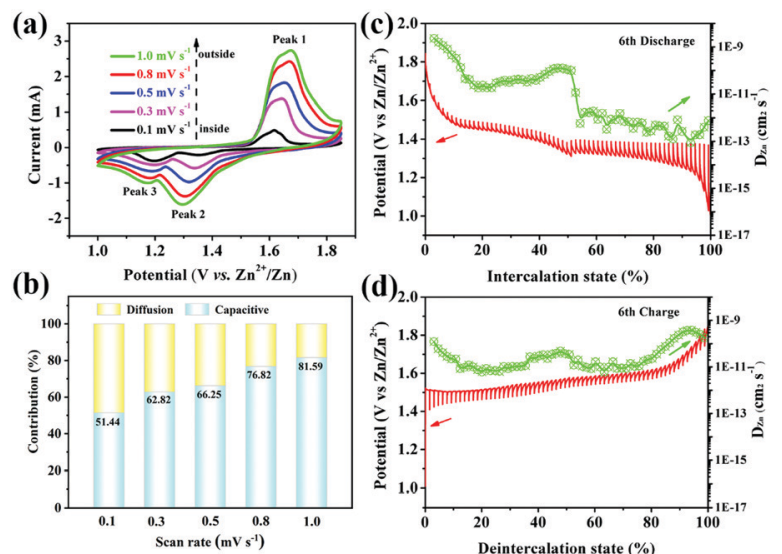

Fig. 5 (a) $\mathrm{CV}$ profiles of $\mathrm{MnO}_{2}-\mathrm{NHCSs}$ at varied scan rates, (b) the proportion of capacitive contributions at varied scan rates, and (c and d) GITT profiles and the corresponding calculated $D_{\mathrm{Zn}}$ values during the discharge and charge process.

in Fig. S8 (ESI $\dagger$ ) for the $\mathrm{MnO}_{2}-\mathrm{NHCS}$ cathode, the $b$ values for peak 1 , peak 2 , and peak 3 are $0.74,0.89$, and 0.50 , respectively, implying that the dual contributions of capacitance and diffusion coexist during the cycling. Among these, the capacitive contribution can be calculated based on eqn (2):

$$
i=k_{1} v+k_{2} v^{1 / 2}
$$

where $k_{1} v$ represents the portion of capacitance controlled by the surface capacitive process, whereas $k_{2} v^{1 / 2}$ stands for the contribution derived from the diffusion-induced insertion process. The percentage of capacitive contributions at varied scan rates is shown in Fig. 5b, from which we can notice that the capacitive contribution increases gradually from $51.44 \%$ at $0.1 \mathrm{mV} \mathrm{s}^{-1}$ to a maximum value of $81.59 \%$ at $1.0 \mathrm{mV} \mathrm{s}^{-1}$. The results indicate that the capacitive-controlled behavior plays the dominant role when scanning at a fast sweep rate, which accounts for the high rate performance. The specific $\mathrm{Zn}^{2+}$ diffusion coefficients $\left(D_{\mathrm{Zn}}\right)$ in different stages during the insertion/extraction process were evaluated by the GITT tests. The detailed testing and calculation process is illustrated in Fig. S9, ESI. $\dagger$ Fig. 5c and d present the GITT curves and corresponding $D_{\mathrm{Zn}}$ values at different (de)intercalation states. On the whole, the calculated $D_{\mathrm{Zn}}$ values during the discharge and charge process are in a magnitude of $10^{-9}-10^{-13} \mathrm{~cm}^{2} \mathrm{~s}^{-1}$ and $10^{-9}-10^{-11} \mathrm{~cm}^{2} \mathrm{~s}^{-1}$, respectively, which is considerably superior to those of other reported Mn-based cathode materials for ZIBs including a- $\mathrm{MnO}_{2},{ }^{40} \mathrm{ZnMn}_{2} \mathrm{O}_{4} / \mathrm{NG},{ }^{23}$ zinc ion stabilized $\mathrm{MnO}_{2}$ nanospheres, ${ }^{41}$ and graphene scrollcoated $\alpha-\mathrm{MnO}_{2}$ nanowires. ${ }^{13}$ Excellent diffusivity is a guarantee of high rate performance. Meanwhile, with respect to the discharge process, the diffusion coefficient of $\mathrm{Zn}^{2+}$ in the second platform is much smaller than that in the first upper voltage platform. Meanwhile, the impedance measurements taken at different discharge states also present similar results (Fig. S10, ESI $\dagger$ ). The charge transfer resistance at $1.4 \mathrm{~V}$ and $1.3 \mathrm{~V}$ (in the range of platform I) is significantly lower than that at $1.2 \mathrm{~V}$ (in the range of platform II), indicating improved electron transfer kinetics of the first plateau. In addition, the sloping line representing the Warbug impedance is much steeper in the upper voltage range than that in the low voltage range, implying a faster diffusion rate. This significant difference may be explained by the $\mathrm{H}^{+}$and $\mathrm{Zn}^{2+}$ co-insertion mechanism. Specifically, considering the much larger size and electrostatic repulsion of $\mathrm{Zn}^{2+}$ than $\mathrm{H}^{+}$, it is highly possible that the $\mathrm{H}^{+}$can be preferentially embedded in the first platform. ${ }^{31,42}$

The enduring cyclic stability at high rates is of great significance for practical applications. Therefore, the long-term GCD tests for the $\mathrm{MnO}_{2}-\mathrm{NHCS}$ electrode at a high current density of $1.0 \mathrm{~A} \mathrm{~g}^{-1}$ were conducted (Fig. 6a). Impressively, the $\mathrm{MnO}_{2}-\mathrm{NHCS}$ electrode is able to display a reversible capacity of $157 \mathrm{~mA} \mathrm{~h} \mathrm{~g}^{-1}$ with a high retention rate of $84.0 \%$ after 650 cycles with about $100 \%$ coulombic efficiency for all cycles, while the $\mathrm{MnO}_{2}-\mathrm{HS}$ electrode displays a low capacity of $72 \mathrm{~mA} \mathrm{~h} \mathrm{~g}{ }^{-1}$ with about $48.3 \%$ capacity retention under identical test conditions, further revealing the outstanding rate capability and superior cycling stability of the as-prepared $\mathrm{MnO}_{2}-\mathrm{NHCS}$ cathode. In addition, even at $2.0 \mathrm{~A} \mathrm{~g}^{-1}$ (Fig. 6b), the $\mathrm{MnO}_{2}-\mathrm{NHCS}$ electrode also illustrates an outstanding reversible capacity as high as $100 \mathrm{~mA} \mathrm{~h} \mathrm{~g}{ }^{-1}$ with a superior retention rate of $78.7 \%$ after 2000 cycles, which is distinctly higher than that delivered by $\mathrm{MnO}_{2}$-HSs. Meanwhile, it is necessary to point out that the capacity contribution of pure NHCSs throughout the entire charging/discharging process is small and basically negligible (Fig. S11, ESI $\dagger$ ). Table S2 (ESI $\dagger$ ) compares the electrochemical performance of the $\mathrm{MnO}_{2}-\mathrm{NHCS}$ electrode with other previously reported manganese-based oxide cathodes, from which we can notice that $\mathrm{MnO}_{2}-\mathrm{NHCSs}$ demonstrate a superior electrochemical performance, not only in rate capability but also on the basis of cycling stability. The excellent performance of the $\mathrm{MnO}_{2}-\mathrm{NHCS}$ electrode can be explained by the following key factors: (1) the unique structure features, including large specific surface area and suitable hierarchical mesoporous distribution, can offer reduced lengths for electron transport and ion diffusion, and thus endow more electrochemically active/ion-insertion sites; (2) the N heteroatom doped hollow carbon spheres as a growth substrate can not only enhance the overall electrical conductivity of the electrode material, but also provide good accommodation of the structural strain and effectively ensure the structural stability upon cycling. ${ }^{43}$ In order to demonstrate whether the electrode can be stable for long-term cycling, the microscopic appearance of the electrode after 100 cycles at $1.0 \mathrm{~A} \mathrm{~g}^{-1}$ was characterized by SEM. As can be seen from Fig. S12 (ESI $\dagger$ ), the nanosphere appearance of the $\mathrm{MnO}_{2}-\mathrm{NHCS}$ electrode can be basically preserved after cycling, and only a small degree of micro-destruction and collapse of the surface nanosheets is observed. Fig. S13 (ESI $\dagger$ ) presents a comparison of the SEM images of the $\mathrm{Zn}$ anode before and after cycling. It should be noted that no zinc dendrites were formed after repeated charging/discharging at $1.0 \mathrm{~A} \mathrm{~g}^{-1}$ for 100 cycles, which is extremely significant for long-term cycle stability. To further illustrate the potential application of this $\mathrm{MnO}_{2}-\mathrm{NHCS}$ electrode, a flexible battery was constructed with xanthan gum electrolyte (see the ESI, $\dagger$ for details). It is noted from Fig. $6 \mathrm{c}$ that the as-fabricated device could deliver a specific energy higher than $200 \mathrm{~W} \mathrm{~h} \mathrm{~kg}^{-1}$ at different states such as 

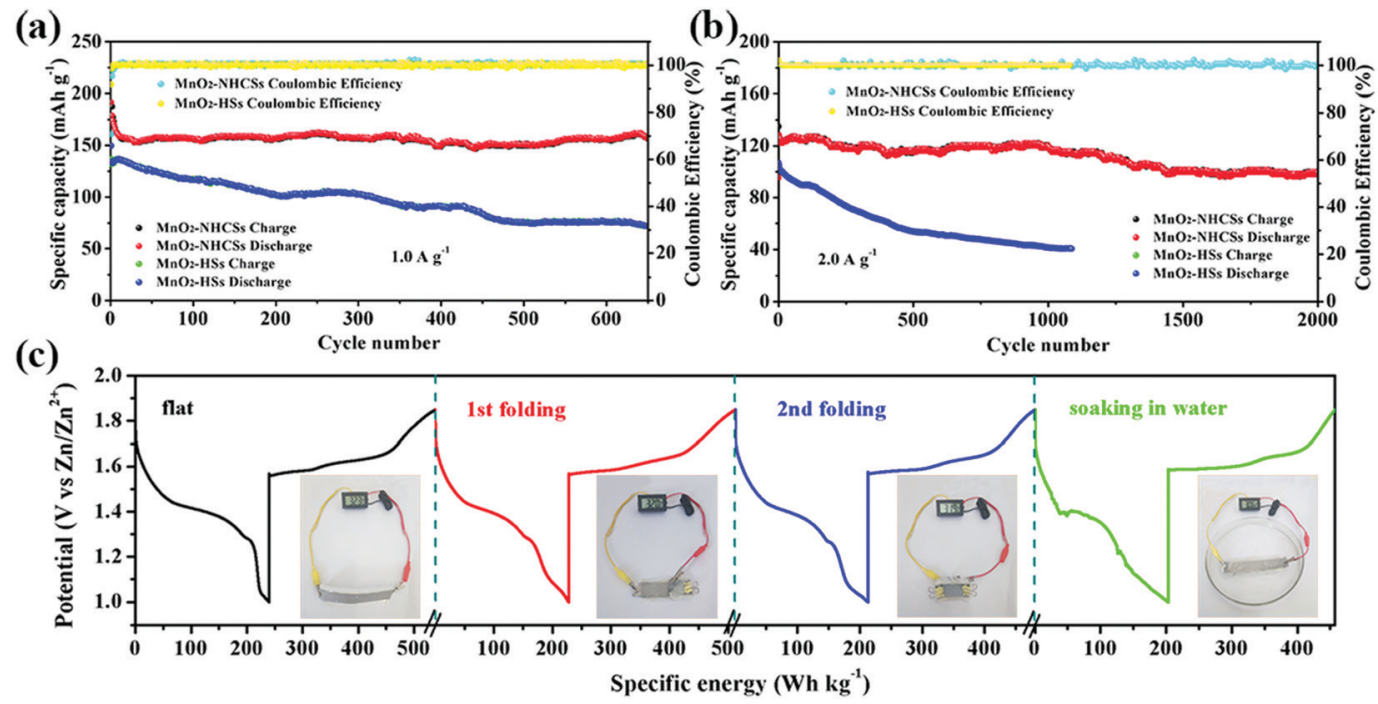

Fig. 6 The cycling stability of $\mathrm{MnO}_{2}-\mathrm{NHCSs}$ and $\mathrm{MnO}_{2}-\mathrm{HSs}$ at high rates of (a) $1.0 \mathrm{~A} \mathrm{~g}^{-1}$ and (b) $2.0 \mathrm{~A} \mathrm{~g}^{-1}$. (c) GCD curves of the flexible Zn/MnO${ }_{2}^{-}$ $\mathrm{NHCSs}$ batteries, and the insets show the digital photos of the flexible battery powering a $1.5 \mathrm{~V}$ temperature sensor.

folding and soaking in water without deteriorating the discharge profile obviously, and it can power a $1.5 \mathrm{~V}$ temperature sensor under various conditions.

In order to reveal the zinc storage mechanism of the $\mathrm{MnO}_{2}-$ NHCS electrode, ex situ XRD patterns under different charge/ discharge states in the first cycle were investigated, as shown in Fig. S14 (ESI $\dagger$ ). During the discharge process, a set of new peaks located at $16.5^{\circ}, 21.3^{\circ}, 24.4^{\circ}, 25.3^{\circ}$, and $33.0^{\circ}$ were observed, which can be ascribed to the zinc hydroxide sulfate hydrate $\mathrm{ZnSO}_{4}\left[\mathrm{Zn}(\mathrm{OH})_{2}\right]_{3} \cdot 5 \mathrm{H}_{2} \mathrm{O}$ (ZSH, JCPDs 78-0246). ${ }^{41}$ Meanwhile, the intensity of these newly appeared peaks continuously enhances with the increase of depth of discharge, and then they disappear in the following reverse charge process, indicating a reversible dissolution/precipitation of the ZSH phase. Besides, some small new peaks at $31.8^{\circ}$ and $33.5^{\circ}$ in the discharged states are attributable to $\mathrm{MnOOH}$ (JCPDs 24-0713), and other emerging peaks with $2 \theta$ values of $15.4,27.7,35.1$, and 37.3 can be indexed to the $\mathrm{Zn}$-inserted phases $\mathrm{Zn}_{x} \mathrm{MnO}_{2} \cdot{ }^{44,45}$ The formation of $\mathrm{ZSH}$ and $\mathrm{MnOOH}$ new phases is generally considered to be related to the decomposition of water and the insertion of hydrogen protons. Interestingly, all new phases cannot be detected in the complete charge state, and all characteristic diffraction peaks of $\mathrm{MnO}_{2}$ can be restored to the initial state, demonstrating a reversible zinc storage mechanism involving $\mathrm{H}^{+} / \mathrm{Zn}^{2+}$ insertion/ extraction processes and the ZSH dissolution/precipitation reaction. In addition, the crystal structure of the $\mathrm{MnO}_{2}-\mathrm{NHCSs}$ can be well maintained after hundreds of cycles (Fig. S15, ESI $\dagger$ ), showing good structural stability. Ex situ XPS analysis of the $\mathrm{MnO}_{2}-\mathrm{NHCS}$ electrode at fully discharged/charged states was also performed to further reveal the elemental composition and the valence change, as displayed in Fig. S16 (ESI $\dagger$ ). In the high resolution Zn 2p spectrum (Fig. S16a, ESI $\dagger$ ), two obvious peaks indexed to $\mathrm{Zn} 2 \mathrm{p}_{3 / 2}(1022.5 \mathrm{eV})$ and $\mathrm{Zn} 2 \mathrm{p}_{1 / 2}(1045.5 \mathrm{eV})$ were noticed when discharging to $1.0 \mathrm{~V}$, further implying the intercalation of zinc ions and the formation of $\mathrm{ZSH}$, being consistent with the ex situ
XRD results. However, in the fully charged state, there are still some $\mathrm{Zn} 2 \mathrm{p}$ signals captured that may be caused by incomplete release of inserted $\mathrm{Zn}^{2+}$ from the lattice. Fig. S16b (ESI $\dagger$ ) presents the Mn2p core-level XPS spectra. After being fully discharged, $\mathrm{Mn}^{4+}$ is partially reduced to $\mathrm{Mn}^{3+}$ and $\mathrm{Mn}^{2+}$. Conversely, the $\mathrm{Mn}^{4+}$ signal increases accompanied by the $\mathrm{Mn}^{2+}$ signal obviously decreasing after fully recharging; meanwhile, the increase of the $\mathrm{Mn}$ valence can be clearly illustrated by the slightly reduced peak energy difference values of Mn 3s for the extraction state (Fig. S16c, ESI†), further confirming the reversible charge transfer in Mn upon cycling.

\section{Conclusions}

In summary, a novel composite of $\mathrm{MnO}_{2}-\mathrm{NHCSs}$ with an NHCS core and ultrathin $\mathrm{MnO}_{2}$ nanoflake shell was successfully prepared. NHCSs as the growth matrix can not only effectively prevent aggregation of the $\mathrm{MnO}_{2}$ nanosheets and maximize the exposure of active sites, but also provide a buffer space for the volumetric expansion and resist the strain arising from the repeated discharge-charge processes. Moreover, the presence of NHCSs can significantly improve the electrical conductivity of the composite. When employed as a cathode material for AZIBs, it displays a high specific discharge capacity (349 $\mathrm{mA} \mathrm{h} \mathrm{g}^{-1}$ at $0.1 \mathrm{~A} \mathrm{~g}^{-1}$ after 80 cycles) as well as outstanding stable cycling ability (cycling for 2000 cycles with a high retention rate of $78.7 \%$ at $2.0 \mathrm{~A} \mathrm{~g}^{-1}$ ). In addition, the superior electrode can be extended to the field of flexible batteries. This work might provide a new strategy for exploring high-performance cathode materials with exceptional rate capability and long cycling stability for practical AZIBs and other energy storage systems.

\section{Conflicts of interest}

There are no conflicts to declare. 


\section{Acknowledgements}

This work was supported by the Natural Science Foundation of China (No. 21371180) and Hunan Provincial Science and Technology Plan Project (No. 2017TP1001).

\section{Notes and references}

1 P. Yu, Y. X. Zeng, H. Z. Zhang, M. H. Yu, Y. X. Tong and X. H. Lu, Small, 2019, 15, 1804760.

2 L. T. Ma, Y. W. Zhao, X. X. Ji, J. Zeng, Q. Yang, Y. Guo, Z. D. Huang, X. L. Li, J. Yu and C. Y. Zhi, Adv. Energy Mater., 2019, 9, 1900509.

3 L. M. Wang, Z. H. Yang, X. Chen, H. G. Qin and P. Yan, J. Power Sources, 2018, 396, 615-620.

4 C. J. Xu, B. H. Li, H. D. Du and F. Y. Kang, Angew. Chem., Int. Ed., 2012, 51, 933-935.

5 B. Y. Tang, L. T. Shan, S. Q. Liang and J. Zhou, Energy Environ. Sci., 2019, 12, 3288-3304.

6 M. Song, H. Tan, D. L. Chao and H. J. Fan, Adv. Funct. Mater., 2018, 28, 1802564.

7 G. Z. Fang, J. Zhou, A. Q. Pan and S. Q. Liang, ACS Energy Lett., 2018, 3, 2480-2501.

8 S. N. Yang, M. S. Zhang, X. W. Wu, X. S. Wu, F. H. Zeng, Y. T. Li, S. Y. Duan, D. H. Fan, Y. Yang and X. M. Wu, J. Electroanal. Chem., 2019, 832, 69-74.

9 M. H. Alfaruqi, V. Mathew, J. Gim, S. Kim, J. Song, J. P. Baboo, S. H. Choi and J. Kim, Chem. Mater., 2015, 27, 3609-3620.

10 S. Zhang, N. S. Yu, S. Zeng, S. S. Zhou, M. H. Chen, J. T. Di and Q. W. Li, J. Mater. Chem. A, 2018, 6, 12237.

11 C. Y. Zhu, G. Z. Fang, S. Q. Liang, Z. X. Chen, Z. Q. Wang, J. Y. Ma, H. Wang, B. Y. Tang, X. S. Zheng and J. Zhou, Energy Storage Materials, 2019, DOI: 10.1016/j.ensm.2019.07.030.

12 M. H. Alfaruqi, S. Islam, V. Mathew, J. J. Song, S. J. Kim, D. P. Tung, J. Jo, S. Kim, J. P. Baboo, Z. L. Xiu and J. Kim, Appl. Surf. Sci., 2017, 404, 435-442.

13 B. K. Wu, G. B. Zhang, M. Y. Yan, T. F. Xiong, P. He, L. He, X. Xu and L. Q. Mai, Small, 2018, 14, 1703850.

14 C. F. Dong, J. W. Liang, Y. Y. He, C. C. Li, X. X. Chen, L. J. Guo, F. Tian, Y. T. Qian and L. Q. Xu, ACS Nano, 2018, 12, 8277-8287.

15 C. F. Dong, L. J. Guo, Y. Y. He, L. M. Shang, Y. T. Qian and L. Q. Xu, Nanoscale, 2018, 10, 2804-2811.

16 Y. Q. Fu, Q. L. Wei, G. X. Zhang, X. M. Wang, J. H. Zhang, Y. F. Hu, D. N. Wang, L. Zuin, T. Zhou, Y. C. Wu and S. H. Sun, Adv. Energy Mater., 2018, 8, 1801445.

17 C. Liu, J. Wang, J. S. Li, R. Luo, J. Y. Shen, X. Y. Sun, W. Q. Han and L. J. Wang, ACS Appl. Mater. Interfaces, 2015, 7, 18609-18617.

18 R. Watanabe, T. Yokoi, E. Kobayashi, Y. Otsuka, A. Shimojima, T. Okubo and T. Tatsumi, J. Colloid Interface Sci., 2011, 360, 1-7.

19 H. L. Fan, F. Ran, X. X. Zhang, H. M. Song, X. Q. Niu, L. B. Kong and L. Kang, Nano-Micro Lett., 2015, 7, 59-67.

20 C. M. S. Anandhi, S. Premkumar, R. M. Asath, T. Mathavan and A. M. F. Benial, AIP Conf. Proc., 2016, 1728, 020456.

21 R. Illathvalappil, L. George and S. Kurungot, ACS Appl. Energy Mater., 2019, 2, 4987-4998.
22 D. H. Wang, L. F. Wang, G. J. Liang, H. F. Li, Z. X. Liu, Z. J. Tang, J. B. Liang and C. Y. Zhi, ACS Nano, 2019, 13, 10643-10652.

23 L. L. Chen, Z. H. Yang, H. G. Qin, X. Zeng and J. L. Meng, J. Power Sources, 2019, 425, 162-169.

24 A. Ogata, S. Komaba, R. Baddour-Hadjean, J. P. Pereira-Ramos and N. Kumagai, Electrochim. Acta, 2008, 53, 3084-3093.

25 T. Xiong, Z. G. Yu, H. Wu, Y. Du, Q. Xie, J. Chen, Y. W. Zhang, S. J. Pennycook, W. S. V. Lee and J. Xue, Adv. Energy Mater., 2019, 9, 1803815.

26 C. Guo, H. M. Liu, J. F. Li, Z. G. Hou, J. W. Liang, J. Zhou, Y. C. Zhu and Y. T. Qian, Electrochim. Acta, 2019, 304, 370-377.

27 T. Liu, C. J. Jiang, W. You and J. G. Yu, J. Mater. Chem. A, 2017, 5, 8635-8643.

28 Q. Sun, B. J. Xi, J. Y. Li, H. Z. Mao, X. J. Ma, J. W. Liang, J. K. Feng and S. L. Xiong, Adv. Energy Mater., 2018, 8, 1800595.

29 H. Zhang, H. Y. Li, H. Y. Wang, K. J. He, S. Y. Wang, Y. G. Tang and J. J. Chen, J. Power Sources, 2015, 280, 640-648.

30 Y. Li, M. M. Zhang, D. H. Pan, Y. Wang, J. M. Xie, Z. X. Yan and J. J. Jing, J. Alloys Compd., 2017, 722, 903-912.

31 J. H. Huang, Z. Wang, M. Y. Hou, X. L. Dong, Y. Liu, Y. G. Wang and Y. Y. Xia, Nat. Commun., 2018, 9, 2906.

32 K. W. Knehr, T. Hodson, C. Bommier, G. Davies, A. Kim and D. A. Steingart, Joule, 2018, 2, 1146-1159.

33 X. Z. Liao, Z. F. Ma, Y. S. He, X. M. Zhang, L. Wang and Y. Jiang, J. Electrochem. Soc., 2005, 152, A1969-A1973.

34 N. Zhang, F. Y. Cheng, Y. C. Liu, Q. Zhao, K. X. Lei, C. C. Chen, X. S. Liu and J. Chen, J. Am. Chem. Soc., 2016, 138, 12894-12901.

35 C. Y. Zhu, G. Z. Fang, J. Zhou, J. H. Guo, Z. Q. Wang, C. Wang, J. Y. Li, Y. Tang and S. Q. Liang, J. Mater. Chem. A, 2018, 6, 9677-9683.

36 B. Z. Jiang, C. J. Xu, C. L. Wu, L. B. Dong, J. Li and F. Y. Kang, Electrochim. Acta, 2017, 229, 422-428.

37 M. H. Alfaruqi, J. Gim, S. J. Kim, J. J. Song, D. T. Pham, J. Jo, Z. L. Xiu, V. Mathew and J. Kim, Electrochem. Commun., 2015, 60, 121-125.

38 J. Lee, J. B. Ju, W. I. Cho, B. W. Cho and S. H. Oh, Electrochim. Acta, 2013, 112, 138-143.

39 F. Liu, Z. X. Chen, G. Z. Fang, Z. Q. Wang, Y. S. Cai, B. Y. Tang, J. Zhou and S. Q. Liang, Nano-Micro Lett., 2019, 11, 25.

40 B. Lee, H. R. Lee, H. Kim, K. Y. Chung, B. W. Cho and S. H. Oh, Chem. Commun., 2015, 51, 9265-9268.

41 J. J. Wang, J. G. Wang, H. Y. Liu, C. G. Wei and F. Y. Kang, J. Mater. Chem. A, 2019, 7, 13727-13735.

42 W. Sun, F. Wang, S. Hou, C. Y. Yang, X. L. Fan, Z. H. Ma, T. Gao, F. D. Han, R. Z. Hu, M. Zhu and C. S. Wang, J. Am. Chem. Soc., 2017, 139, 9775-9778.

43 W. Qiu, Y. Li, A. You, Z. M. Zhang, G. F. Li, X. H. Lu and Y. X. Tong, J. Mater. Chem. A, 2017, 5, 14838-14846.

44 M. H. Alfaruqi, S. Islam, D. Y. Putro, V. Mathew, S. Kim, J. Jo, S. Kim, Y. K. Sun, K. Kim and J. Kim, Electrochim. Acta, 2018, 276, 1-11.

45 Y. Jin, L. F. Zou, L. L. Liu, M. H. Engelhard, R. L. Patel, Z. Nie, K. S. Han, Y. Shao, C. M. Wang, J. Zhu, H. L. Pan and J. Liu, Adv. Mater., 2019, 31, 1900567. 